Article

\title{
Review Pollution: Pedagogy for a Post-Truth Society
}

\author{
Emily West \\ Department of Communication, University of Massachusetts Amherst, USA; E-Mail: ewest@comm.umass.edu
}

Submitted: 15 January 2021 | Accepted: 6 April 2021 | Published: 5 August 2021

\begin{abstract}
Consumer reviews on platforms like Amazon are summarized into star ratings, used to weight search results, and consulted by consumers to guide purchase decisions. They are emblematic of the interactive digital environment that has purportedly transferred power from marketers to 'regular people,' and yet they represent the infiltration of promotional concerns into online information, as has occurred in search and social media content. Consumers' ratings and reviews do promotional work for brands-not just for products but the platforms that host reviews-that money can't always buy. Gains in power by consumers are quickly met with new strategies of control by companies who depend on reviews for reputational capital. Focusing on ecommerce giant Amazon, this article examines the complexities of online reviews, where individual efforts to provide product feedback and help others make choices become transformed into an information commodity and promotional vehicle. It acknowledges the ambiguous nature of reviews due to the rise of industries and business practices that influence or fake reviews as a promotional strategy. In response are yet other business practices and platform policies aiming to provide better information to consumers, protect the image of platforms that host reviews, and punish 'bad actors' in competitive markets. The complexity in the production, regulation, and manipulation of product ratings and reviews illustrates how the high stakes of attention in digital spaces create fertile ground for disinformation, which only emphasizes to users that they inhabit a 'post-truth' reality online.
\end{abstract}

\section{Keywords}

consumer empowerment; disinformation; online reviews; platforms; reputation economy

\section{Issue}

This article is part of the issue "Complexity, Hybridity, Liminality: Challenges of Researching Contemporary Promotional Cultures" edited by lan Somerville (University of Leicester, UK) and Lee Edwards (London School of Economics and Political Science, UK).

(C) 2021 by the author; licensee Cogitatio (Lisbon, Portugal). This article is licensed under a Creative Commons Attribution 4.0 International License (CC BY).

\section{Introduction}

Consumer reviews seem to fulfill the promise of an interactive digital environment transferring power from marketers to 'regular people' (Kuehn, 2017; Novak, 2021). The ubiquitous gold and red stars representing user ratings are a constant in the aesthetics and rhetorics of digital space being more user-centered and democratic than pre-digital markets. Feedback from ordinary users represents the values of Web 2.0, a metaphor describing how the web has steadily offered more interactivity, making the internet a more participatory and democratic space (DiNucci, 1999; O'Reilly, 2005). Yelp, a reviewing app for restaurants and other local businesses, used the slogan "Real People, Real Reviews" for a time, presenting itselfKuehn (2017) argues-as a "review democracy" (p. 206).
Ratings and reviews did not originate with Web 2.0, even if they seem native to this era. Travel guidebooks from the 19th century introduced a star-rating system to indicate sights of special interest and hotels of quality (Bruce, 2010). Star rating systems were then adopted by restaurant and film reviewers in the first half of the 20th century (Bialik, 2009; Harp, 2002). Whereas star ratings historically were a summary of an individual reviewer's evaluation, decades later, websites like Metacritic and Rotten Tomatoes added the innovation of aggregating critic ratings, just as consumer ratings were being datafied on sites like Amazon. As with so much that accrues value online, it's through aggregation that ratings acquire their impact, providing an impression-ata-glance to the prospective consumer, bragging rights or a tarnished image for the product brand, a valuable 
information commodity for the platform, and a key data point for the platform's algorithms. By quantifying subjective responses to a product, be it a book or a household item, star-ratings flatten the qualitative differences among products and place them for linear comparison, be it on number of stars, number of ratings, or a combination of both. While this might be frustrating to producers and brands, it's also understandable that consumers seek out and rely on these ratings to navigate an ecommerce environment of overwhelming abundance (Graham \& Henman, 2019).

Consumer reviews reflect theorizations of late capitalism that focus on the circulation of information and affect. Political theorist Dean (2005) has warned against the fantasies of abundance and participation offered by the current state of "communicative capitalism." Whereas in previous communication environments, Dean argues, we would communicate "messages" with a particular use-value to which we expected some kind of response, in a socially-networked setting of abundance, we make "contributions" that through their circulation acquire exchange value, but to which we are much less likely to get a response (p. 58). Leaving online reviews and ratings on ecommerce sites very much fits Dean's critique, where we may feel called on to participate, even though our individual contribution is unlikely to register. It is only at volume and wide circulation that reviews in aggregate begin to 'count.' In fact, the more reviews are created, the less likely one particular review will be read or make an impact. Dean's concern is that these voluminous expressions of popular will in the marketplace are embraced as 'democratic' when actual political governance is far from it. In communicative capitalism, Dean writes, "commercial choices" are treated as "the paradigmatic form of choice per se" (p. 55). "Communicative exchanges," commonly understood to be foundational to the working of democracy, actually uphold "capitalist production" rather than democratic governance (p. 56).

Communication scholar Hearn (2010) offers a similar critique, adding a focus on affect as central to how markets work in late, and particularly digital, capitalism: "If markets are conversations, then value must be generated through our visible, affective and quantifiable participation in these conversations" (pp. 421-422). This "fragile, fluid enactment of value" is reputational capital, a component of symbolic capital, argues Cronin (2016), that must be continuously accumulated and circulated, rather than earned once and for all (p. 399). Hearn (2010) identifies online rating and ranking systems as "places where the expression of feeling is ostensibly constituted as 'reputation' and then mined for value" (p. 422).

Reviews are both informational and affective, and affect drives attention. Tech theorist Goldhaber (1997) offers the attention economy as a fundamental concept for understanding the internet's impact on the circulation of value, suggesting that the scarcity of attention resulting from the explosion in information has become a significant shaper of society relative even to the scarcity of money or natural resources. Attention breeds attention, to the point that attention becomes its own currency. The star rating purports to index both attention and affect, and has become practically a pre-requisite to selling on Amazon.

As Dean and Hearn imply, consumer ratings and reviews are an example of the "free labor" that ordinary users perform that creates value, for platforms especially (Terranova, 2000). Critical scholars studying this online practice question how users are encouraged to 'participate' in ways that primarily benefit large corporations, cultivating an ethos or aesthetic of democratization rather than concrete gains in the distribution of power (Kuehn, 2017; Novak, 2021). Hearn (2010), for example, questions whether the 'wisdom of the crowd' really "signals the rise of a new form of ethical politics," since digital reputation functions "through forms of market discipline and affective conditioning... which work to direct human meaning-making and self-identity in highly motivated and profitable ways" (p. 423).

On the other hand, consumer reviews do level the playing field between business and consumers at least to an extent, allowing consumers to warn others about bad products and services, or rave about those that shine. Based on interviews with Yelp reviewers, Kuehn reports that "participants were committed to empowering consumers to make the best of available choices," describing their reviews as a "public service" and even a "job" (2017, pp. 212-213). Sellers are certainly very aware of the newly empowered consumer, and seem to dispute the concern that a single online review has no impact. A book aimed at prospective sellers on Amazon observes:

Never before has a single consumer-driven action had this kind of immediate weight and capability to catapult a new brand to success. In the days before eComm and social media, consumers who bought your product in a store could love it or hate it but you might never know exactly what they thought or why. Now, one product review can reach the entire world, and the impact this has on your brand reputation cannot be overstated. (McGinn \& Segal, 2019, p. 76)

But as in so many power relationships, gains by consumers are quickly met with strategies of control. Consumer review spaces initially granted more voice to consumers to punish and reward market actors. But as the promotional value of consumer ratings has become clearer, especially for new players with less brand recognition who see the opportunity in ecommerce to compete in many product areas, the businesses being reviewed have sought to exert greater control over them, whether subtly incentivizing high ratings, or blatantly gaming the system with fraudulent content.

Both product brands and platform brands encourage consumers to provide reviews and consult others' feedback in their purchase decisions. But when it comes 
to the quality of reviews, platforms generally prioritize authenticity, since the success of their brands depends on trust. There are exceptions, since positive reviews can ingratiate ad-buying clients (e.g., allegations that Yelp adjusted positive vs. negative reviews depending on whether businesses advertised on the site; Tsukayama, 2013), and well-reviewed products drive sales of which the platform may take a cut. While platform brands balance their desire for authentic reviews with these other considerations, many sellers do whatever it takes to create more and better reviews that trigger advantageous search results and sales (He et al., 2020).

What has emerged is a field within the reputation economy where the promotional value of a four- or fivestar rating and glowing reviews in a consumer's authentic voice is a central contested resource. As with information disorder more generally, the decline of gatekeepers like buyers at large retailers and arms-length review publications like Consumer Reports initially democratized the sphere of product evaluation and helped many more players enter the marketplace. However, the decline of gatekeepers has also sown chaos in the information environment. In the realm of consumer reviews, this has resulted in layers of rules, regulations, and ways to evaluate the authenticity of reviews by a variety of organizations, followed by efforts to game and circumvent those structures by sellers and reviewers-for-hire. The contested space of product reviews is also a contested space in terms of who wins the consumer's trust, and whose version of the 'truth' prevails. From the consumer's perspective, either they proceed with little knowledge of review pollution and end up sometimes purchasing poor quality products as a result, or, if informed about the push-and-pull around consumer ratings and reviews, they learn how fierce the jockeying is when consumer attention is at stake. Although social media platforms like Facebook and YouTube have attracted the most attention as sites of information disorder, ecommerce platforms like Amazon should not get a pass, especially when the ratings and reviews being gamed send unsafe products, or books and films with disinformation about health, history, and science to the top of the search results (DiResta, 2019). "Computational propaganda and influence operations," DiResta (2018) points out, "are inexpensive, they appear to be effective, and the tech platforms that built the infrastructure are having a very difficult time stopping them" (p. 25). We'll see that this is certainly true for Amazon, which increasingly struggles to manage its reviews space.

The rise of disinformation is associated with what some describe as our contemporary 'post-truth' era. However, to some extent, consumer ratings and reviews are not trading in 'truth.' Esposito and Stark (2019) argue that users recognize that, as "second-order observations" of reality, reviews will be rife with subjectivity and error, but their utility in the face of complexity overrides that concern (p. 12). But even if the relationship between product ratings and 'reality' is tenuous, the relative posi- tion of whatever is rated within a given system comes to have the force of empirical comparison, creating its own promotional reality (Cronin, 2016). The term 'post-truth,' identified by the Oxford Dictionaries (Oxford Languages, 2016) as Word of the Year in 2016, is understood in a variety of ways, from the downgrading of facts and evidence in favor of beliefs and emotion, and the prevalence of lies and "bullshit" in public life, to the use of distractions and strategic silences to divert audiences from uncomfortable facts (Keane, 2018, para. 13). The muddying of information and promotion is just one variant of 'post-truth,' and not a new one. While consumers have always been wary of the ways promotion can manipulate, digital space presents users with the blending of information and promotion at every turn. We see it in search results, recommendation algorithms, undisclosed promotional considerations from influencers, and native advertising. Even when it's just everyday products with manipulated ratings, the disinformation that creeps into almost every corner of online activity teaches a broader lesson about the state of our 'post-truth' society to consumers. The sense that all digital information is rife with manipulation and promotionalism erodes trust in platforms, fellow participants, and information itself (Amazeen \& Muddiman, 2018; DiResta, 2018; Kozinets, et al., 2020).

This article examines the complexities of product reviews and ratings on Amazon, where individual efforts to provide businesses with feedback and help others make consumer choices become transformed into an information commodity and promotional vehicle. With estimates of Amazon's market dominance ranging between $37 \%$ and $50 \%$ of US ecommerce sales, every decision that Amazon makes regarding its reviews is consequential for the fortunes of sellers and the information available to consumers (eMarketer Editors, 2020; Wells et al., 2019). A close examination of Amazon's reviews space reveals an ongoing tug-of-war between a tech giant that recognizes the value of reviews for driving sales and for the platform's informational value to consumers, and the third-party sellers for whom Amazon is practically the only game in town.

\section{Amazon Ratings in the Reputation Economy}

Hearn writes, "reputation is a cultural product, and as such is conditioned by its mode of production" (2010, pp. 423-444). So, what is the mode of production for Amazon reviews, and how has this changed over time? Amazon was one of the first commercial spaces to allow users to post their own reviews, doing so since the site's launch in 1995. These reviews appeared alongside editorial content that Amazon invested in heavily in its early years, in order to make its site feel like a legitimate place that provided useful information to the consumer who couldn't leaf through books or consult a sales associate. Amazon offered both these "modalities of truth" to users, based in authoritative expertise as 
well as the experiences of ordinary consumers, in order to build much-needed trust and overcome hesitancy in the early days of online shopping (Graham \& Henman, 2019 , pp. 2015-2016). Amazon invited site users to indicate if consumer reviews were 'Helpful' or 'Not Helpful,' and also allowed them to comment on them (the option to 'downvote' a review was phased out starting in 2016, see Marth, 2016; and the comment feature was removed in 2020, see Dawson, 2020; although a 'Report Abuse' button appears under each review). In the earliest days of ecommerce, Amazon's review architecture anticipated the world of likes and hearts and upvotes that we now inhabit online.

By the late 1990s, the expense of hiring editors and book reviewers compared to the efficiency of free crowdsourced reviews became clearer to the company that has consistently favored platform logics of 'selfservice' over paying people to do things (Marcus, 2004). For many years, consumer reviews were a useful but rarely remarked upon feature of the site, as indicated by press coverage. But a number of developments made reviews a target for manipulation. In 1999, Amazon opened its platform up to third-party sellers. Then, in 2005 with the development of the Prime membership, where consumers in the US (at least, initially) could pay an annual fee for free two-day shipping, vastly more consumers and sellers flocked to the site, soon making Amazon the first stop for online shoppers. The product selection exploded again in the mid-2010's when Amazon made it easier for foreign companies to use its marketplace, and Chinese sellers in particular flooded the site with new products (Shepard, 2017). The advantage that a platform accrues due to network effectsthe greatest number of sellers, the biggest variety of products, and the largest crowd of shoppers-made a product's rating on Amazon disproportionately impactful on sales, both on and off Amazon's site since shoppers may do product research on Amazon but buy elsewhere. As articulated in the business literature, "there is no other platform with Amazon's scale, reach, and buying intent" (McGinn \& Segal, 2019, pp. 15-16).

Third-party sellers are right to be concerned about the volume and quality of reviews for their products. According to a 2018 survey by Pew, 93\% of Americans consult customer reviews when buying a product for the first time (Turner \& Rainie, 2020). Ratings make a measurable difference in sales, especially for new or lesser-known products and brands. One ecommerce consultant even argues that "reviews are more important than a brand," observing that "there's major brands that are being crushed by small direct-to-Amazon or direct-to-consumer brands" (Matsakis, 2019, para. 6). Business scholar Luca (2011) found that a one-star difference in Yelp ratings was associated with a 5 to $9 \%$ increase in revenue for Seattle-area restaurants. In contrast, an ecommerce consultant estimates that a one-star rating increase results in a $26 \%$ increase in product sales on Amazon (Nguyen, 2019b), a claim reinforced by He et al.'s (2020) findings of large and statistically significant improvements in product sales and search ranking after sellers bought fake reviews on Facebook groups, at least in the short term. The importance of Amazon reviews and ratings for new products is clear from the frequency with which press releases tout a new product's star ratings and reviews (e.g., "Reusable kids' icePack," 2020).

Ranking high in search on Amazon is crucial for visibility, or 'discoverability,' and therefore for sales. According to Amazon, "70\% of customers never click past the first page of search results," and "the first three items displayed in search results account for $64 \%$ of clicks" (CPC Strategy, 2018, p. 22). Although the specifics of the A9 ranking algorithm, Amazon's search algorithm, are proprietary, the received wisdom among sellers is that the primary factors driving search ranking are: relevance of product key terms to search terms, sales velocity, price, and product availability (Dod, n.d.; Feedvisor, n.d.; McGinn \& Segal, 2019). Opinion differs on whether ratings (both the volume of ratings and the average rating) are directly considered by the algorithm, or whether their influence is indirect via impact on sales. Regardless of whether star ratings factor in directly or indirectly, it's clear from the trade press and business services companies targeting Amazon sellers that this constituency believes they matter, making them part of Amazon's "algorithmic imaginary" (Bucher, 2017). In many ways Amazon's site has opened the world of retail up to more sellers, particularly small businesses, by allowing them to circumvent the gatekeeping of retail buyers and limited distribution networks. However, as Andrejevic et al. (2015) have pointed out, "information organizers" like Amazon are "the new gatekeepers," and their control over the information used in these algorithms and the priorities "baked into" them shape our information landscape just as traditional gatekeepers did, but in different ways (p. 386).

Product reviews suffer from serious grade inflation. A 2014 study found a sample of Amazon books were reviewed with five stars on average $59 \%$ of the time, with only $4.8 \%$ of the reviews having only one star (Anderson $\&$ Simester, 2014). And average ratings have only been going up since then, correlating with an increase in efforts to produce incentivized reviews as the number of sellers on Amazon's marketplace has exploded over the last decade (Nguyen, 2018a). He et al. (2020) found that a large sample of more than 200,000 products listed on Amazon had a mean rating of 4.2. Many consumers are mistrustful of products with less than a four-star rating. Kennedy and Hill (2018) argue that "emotions matter for everyday engagements with data," and that data visualizations, such as star ratings, are read not just cognitively but affectively (p. 844). The frequency with which we see products associated with star ratings of four or more has likely imprinted that range as a marker of acceptable quality, conveying comfort and confidence to most consumers. 
Leveraging consumers' positive affect towards the image of the star rating, Amazon has leaned into four or more stars as core to its brand value and identity by opening a new brick-and-mortar store concept called Amazon 4-Star in 2018. As the name suggests, these stores feature products that have received ratings of at least four stars; many products display a favorable customer review in addition to the star rating (see Figure 1). The digital price tags show the exact rating out of five, as well as the number of reviews, just as products appear online.

This store concept instantiates Amazon's desire to be a destination for highly-rated products, and sends the message that the signal of quality is a four- to five-star rating.

\section{Review Pollution}

For the first 10 to 15 years of Amazon's history, its consumer reviews did not attract a great deal of attention, other than being mentioned as an attractive bonus feature of the site. When they did attract attention, it was typically for being humorous, used for 'culture jamming' $-a$ trend that took off in the early 2000s-as in the scathing and hilarious reviews of "Bic Pens for Her," or unintentionally funny, such as reviews for classic books by unimpressed readers (Suddath, 2005).

In 2005 publicly visible concerns about the manipulation of consumer reviews on Amazon's retail platform started to arise. A study by David and Pinch (2006) estimating that $1 \%$ of book reviews on Amazon were, at least in part, copied from other reviews received a fair amount of press attention. By 2010, as Amazon's dominance of ecommerce became undeniable, attention to manipulated reviews started exploding, especially for books. Stories started emerging with some frequency about individual authors covertly writing reviews for their own books as well as their rivals, as well as systematic efforts to game the system through companies whose sole purpose was to produce fake reviews (e.g., Charman-Anderson, 2012; Katz, 2010). Newspapers and magazines started to feature regular pieces on how to spot fake product reviews (e.g., Hagemeier, 2012; The Better Business Bureau, 2017).

Amazon's own rules at this time merely stated that no reviews should be posted by someone with a conflict of interest, and that any form of financial compensation had to be clearly disclosed in the review. In other words, the site did not allow "anyone to write reviews as a form of promotion" without disclosing it as such (Amazon, 2020 b, para. 3). But with few monitoring systems and a structure that allowed anyone with a customer account to post a review, regardless of whether they had bought the product, the feature was ripe for exploitation.

Around the time of Prime's launch in 2005, social media platforms began to explode. Facebook groups and other online spaces, eventually including Slack, Discord, Telegram, and subreddits, became convenient places to recruit people willing to write glowing reviews and leave five-star ratings in exchange for a fee, or even just for the free product or a rebate (Nguyen, 2018a). Sellers also buy Facebook ads offering free products, linking users to chatbots that organize the entire transaction (Nguyen, 2019a).
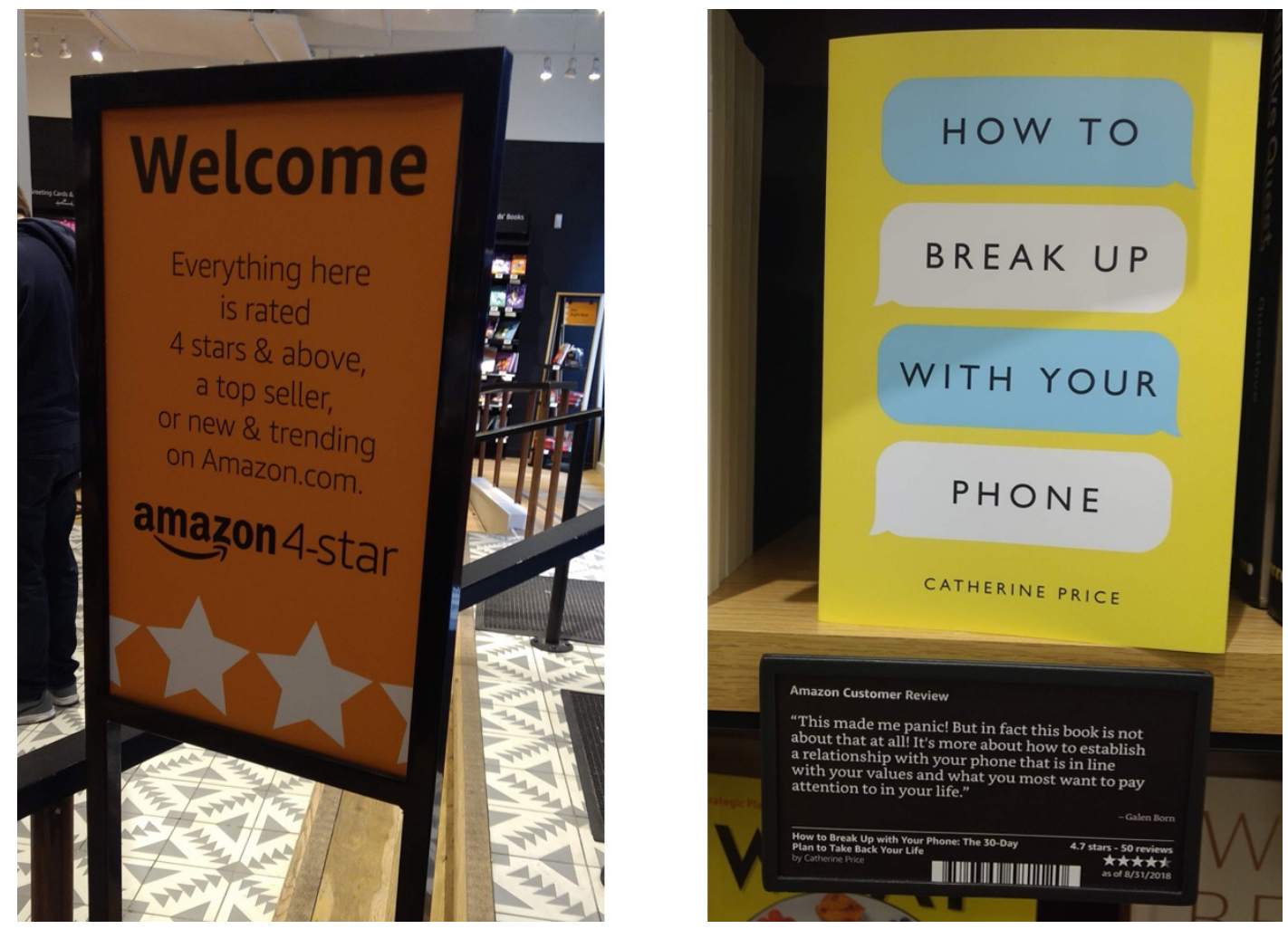

Figure 1. Signage at Amazon 4-Star in New York City. Photos by author. 
By the early 2010s, Amazon started to crack down on review pollution. Since at least 2011, if Amazon has a record of the person leaving the review having actually bought the item, it is labeled as a 'Verified Purchase,' to give users confidence in its authenticity (e.g., Mooney, 2011); consumers can filter reviews so they only see the verified purchases (see Figure 2). In 2015, Amazon launched high-profile lawsuits against individuals and websites known to be posting or facilitating compensated reviews (Mendoza, 2015), and in 2016 Amazon banned reviews incentivized with compensation, even if disclosed (Dwoskin \& Timberg, 2018). Amazon regularly blocks shoppers who are caught or suspected of writing inauthentic or compensated reviews (Dwoskin $\&$ Timberg, 2018). Also since 2015 , verified purchases have greater weight in a product's average rating (Rubin, 2015). Today Amazon explains that a product's average star rating is not a simple mean, but is determined by machine learning that takes into account "how recent the rating or review is and verified purchase status," as well as "multiple criteria that establish the authenticity of the feedback" (Amazon, 2020c, para. 1), including the number of 'helpful' upvotes by site users (Rubin, 2015). Reviews from unverified purchasers are not calculated into a product's average without "more details in the form of text, image, or video" (Amazon, 2020c, para. 2). And now, to even be eligible to post a review, a customer must have spent at least $\$ 50$ on Amazon in the previous 12 months (Amazon, 2020a).

However, Amazon's regulatory moves have merely shaped how companies game the system. Instead of just paying people to post authentic-sounding reviews, sellers now find Amazon account-holders willing to buy the item with their own credit card, leave a review (often after a waiting period, so the review looks more authentic and avoids Amazon's automated systems that flag suspicious review behavior), and then get reimbursed from the company once the review is posted (DiResta,
2019; He et al., 2020; Nguyen, 2018a). Sometimes these arrangements involve a small payment on top of the reimbursement. The expense to the seller is considerable (free goods and shipping, even payments), but both research and industry experience show that, in the shortterm at least, it is effective in improving placement in search rankings and increasing sales (DiResta, 2019; He et al., 2020; Nguyen, 2018a).

The term platform evokes a foundation-some kind of digital space or software capability-that allows different stakeholders (consumers and sellers, or users and advertisers) to interact (Srnicek, 2017). As a platform, Amazon is always serving two constituencies. Amazon's 'number one principle' is customer obsession, but it also needs to serve sellers. As Amazon became more aware of how important consumer reviews were for third-party sellers, it developed in-house programs to connect sellers with reviewers, allowing what the company's rules have not since 2016: giving free products to consumers with the hope of getting them reviewed on Amazon's platform (with the exception of books, since distributing free books to generate reviews is an industry-standard practice). Amazon Vine, launched in 2007, enrolls 'super reviewers' by Amazon's invitation only. The program rewards the company's most enthusiastic and consistent reviewers, while also providing a much-needed opportunity to gain review momentum for sellers. In addition, in 2017 Amazon started the Early Reviewing program that allowed sellers to ask Amazon to contact customers who have purchased a new product and ask them to write an honest review in exchange for a modest (\$1-3) Amazon gift card (Kelley, 2017; but this program was discontinued in 2021, see Masters, 2021).

Amazon is cracking down on fake and incentivized reviews not only because they undermine its most important asset-consumer trust of its brand-but because it wants to funnel these illicit marketing dollars away from third-parties and towards its own advertising platforms.

\begin{tabular}{|c|c|c|c|c|c|}
\hline SORT BY & ILTER BY & & & & \\
\hline Top reviews $\quad \vee$ & All reviewers & All stars & $v$ & Text, image, video & $\checkmark$ \\
\hline 885 global ratings | 109 & Verified purchase only & & & & \\
\hline
\end{tabular}

\section{From the United States}

$$
\text { Q }
$$

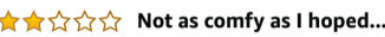

Reviewed in the United States on December 13, 2019

Size: 11 Women/10 Men Color: White/Core Black Verified Purchase

Like many of you reading this, I have been waiting a long time for a Boost slide! I love the feeling of Boost under foot, especially in UltraBoost. I was never a fan of the original Adilette slides because the footbed is just too hard, but I love the more recent Cloudfoam variants and have several pairs that I wear constantly. The idea of having boost slides seemed like it would be great, but it turns out that it's only ok. First of all, these slides are very snug. I wear a 9 in the Cloudfoam slides, but got these in a 10 and they are still very snug - but tolerable. Next, and most disappointingly, the Boost just doesn't feel as good as it does in the Ultraboost, or even something more minimal like an NMD_R1 Primeknit which has about the same about of Boost. Also, I think that the white Boost and outsole looks a little out of place with the black strap. The white ones look better, but the Boost and outsole should definitely be blacked out on the one with the black strap. Also, FYI the item pictured as of today is not the actual item - the ones received have a thin layer of black fabric on the top of the footbed, and the outsole has a different pattern. I let Amazon know so hopefully they will update the picture.

Figure 2. Sorting by Verified Purchases only is one of the options for sorting reviews on Amazon's site. Screenshot by author. 
Amazon would rather sellers pay for Sponsored Products (ads for particular search terms) or Sponsored Brands (banner at top of page after search) or use Amazon's DSP (Demand Side Platform) to buy individually targeted ads. Or, Amazon would rather use sellers' desire for a critical mass of consumer reviews to drive them into expensive Amazon programs like Brand Registry, a prerequisite for enrolling in Amazon's Vine and Early Reviewer programs.

When sellers or government officials complain about fake reviews, Amazon says it spends millions of dollars to ensure their authenticity, including refining machine learning that spots fake reviews by their language, timing, or patterns in customer accounts (DiResta, 2019; Dzieza, 2018; Masters, 2021; Nguyen, 2019b). Over time, Amazon has slowly become a reluctant governor of its reviews space. For example, in 2015 Amazon was heavily criticized for allowing conspiracy theorist 'brigading' in reviews for books written by survivors and parents of victims of the Sandy Hook school shooting in Newtown, CT. Amazon's position was that any authentic reviews should stand on the site, whether the book had been purchased by the reviewer on Amazon or not (many of those posting had certainly neither purchased nor read the books; Greene, 2015). Coordinated campaigns to boost or tank a product (and its associated ideas) weren't a problem, as long as the reviews were real people's real opinions (Greene, 2015). But by 2020, when the novel American Dirt was attracting critical reviews due to its depiction of a Mexican immigrant's experience by a White author, Amazon restricted what reviews could appear to verified purchases, in an effort to prevent the reviews section becoming a forum for political debate, a decision also made for A Very Stable Genius, a book critical of President Trump (Scott, 2020).

In 2019 Amazon made it easier for consumers to give feedback about products, with 'One-Tap Ratings.' This feature, which invites users to rate a product they have purchased with just 'one tap,' rather than the more unwieldy process that required written feedback in order to leave a rating, would seem to invite more fake reviews, and some critics say this has been the outcome ("Report: Fake online reviews," 2020). But Amazon's intent was to get more participation from legitimate, representative purchasers that would hopefully drown out the fake and incentivized reviews that unscrupulous sellers are buying (Del Ray, 2020). This move signals that Amazon thinks there's only so much that can be done about the compensated reviews solicited in Facebook groups and other hard-to-track places on the web. The 'one-tap' solution seeks to turn those reviews into 'noise,' as well as build confidence among consumers from the greater volume of ratings. Some products, particularly popular tech products, have tens of thousands of ratings, such as the Kindle Paperwhite with more than 83,000 ratings, much more than its 28,905 reviews.

The sheer abundance of ratings lends a sheen of democratic authenticity to the aggregated rating, just as Dean (2005) predicts that the abundance of communica- tion facilitated by digital technologies will be leveraged by capital. We're invited to 'participate,' and Amazon has made it as easy as possible, primarily to protect its reputation as a platform with reliable product information from real customers. More ratings, even if they're not connected to written reviews, make sellers happy, build confidence in consumers, and cement Amazon's dominance in product ratings as an information commodity, which in turn contributes to its monopoly-like control of ecommerce in many markets.

Despite Amazon's regulatory efforts, observers say that review pollution is getting worse. Amazon may not be trying hard enough. As DiResta points out, many of the Facebook groups that recruit reviewers are very easy to find (as cited in Dwoskin \& Timberg, 2018), and the changes Amazon has made don't seem proportionate to the scale of the problem (DiResta, 2019). But it's also the case that the strategies sellers use create a game of whack-a-mole for the platform. In addition to the techniques already described, sellers place negative reviews on their competitors' products, engage in suspicious reviewing behavior (such as rapidly posting many 5-star reviews) on their competitors' listings in the hopes of Amazon removing them from the platform (Masters, 2021), hijack well-rated products' listings with their own products (Nguyen, 2018b), create dummy accounts using people's real names and addresses to post fake reviews (Masters, 2021), and hire click-farms to show activity on a product listing in relation to search terms or to vote particular reviews as 'helpful.' As one journalist put it, Amazon "must constantly implement new rules and penalties, which in turn, become tools for new abuses, which require yet more rules to police" (Dzieza, 2018, para. 7).

\section{Conclusions: Governing Review Disinformation}

Amazon's sheer size and dominance of ecommerce make it effectively its own field, in which multiple players vie to come out on top in relation to the company's rules and incentives. Because of Amazon's devotion to automation, a cottage industry of companies has sprung up to help sellers navigate the platform. Often populated by former Amazon employees, companies like Feedvisor and Buy Box Experts help with product listing content, pricing, search engine optimization, advertising strategies, and fulfillment through Amazon. A subset of these companies focus specifically on helping sellers get the critical mass of consumer reviews to boost them in search by using Amazon's automated services that send messages to customers who have bought their product, including Salesbacker and eComEngine. These companies openly advertise their services and operate within the letterif not always the spirit-of Amazon's rules, unlike the countless entities operating in Facebook groups or other hard-to-track places who solicit reviews in contravention of the rules.

While these third-party companies are seller-facing, others have arisen to help the average consumer 
interpret the authenticity of product reviews. Fakespot and ReviewMeta both offer this service, using data science to estimate which reviews are untrustworthy. Fakespot evaluates the reliability of reviews with a letter grade, while ReviewMeta re-calculates a product's average rating with the suspect reviews removed or weighted less. ReviewMeta considers 12 factors in its review evaluations, including the average difference in verified vs. unverified purchases, the degree of phrase repetition in the reviews, past reviewing behavior of the reviewer, and the distribution of reviews over time. These review adjusters aim for transparency in how they judge reviews to be unreliable and how that impacts their overall evaluation, while acknowledging, as ReviewMeta founder Noonan (2016) does, that "unnatural review detection is not an exact science." Indeed, the two services sometimes arrive at different evaluations of the same set of reviews, indicating the degree of interpretation involved (Broida, 2019).

In 2020, with more consumers than ever turning to online shopping during the Covid-19 pandemic, review manipulation appeared to reach, itself, epidemic proportions. Fakespot estimated that $42 \%$ of Amazon reviews from March to September of 2020 were unreliable, up from $36 \%$ in the same period the previous year, a rate previously only seen in peak shopping seasons ("Report: Fake online reviews," 2020). ReviewMeta estimates that the average number of suspicious reviews is higher, greater than $50 \%$ and as high as $2 / 3$ for particular product categories, such as electronics and health aids (including weight-loss pills, testosterone boosters; Dwoskin \& Timberg, 2018). According to testimony from many small sellers, paying for reviews is increasingly seen as just part of the cost of doing business on the platform.

Greater manipulation of its ratings and reviews, combined with more frequent PR challenges around the authenticity of consumer feedback, have pushed Amazon into undertaking greater governance of this aspect of its platform. Amazon knows that "perceived review manipulation" is a threat to the value that consumers see in their ecommerce brand (Xu, 2021, p. 4). Amazon's governance of reviews provides the appearance of action for public relations purposes, and aims also to be pre-emptive against government-the Federal Trade Commission in the US context-taking a greater interest in review authenticity. But the steps Amazon has taken stay within its preferred ways of operating and skew towards systems that tie sellers closer to the company and its paid services. Rather than focusing solely on preventing fraudulent reviews, Amazon has lowered the bar for more consumers to rate the products they buy, consistent with every platform's bias towards greater engagement. Amazon may have disallowed consumers writing reviews for products they received free, or at a deep discount, but they facilitate this exact process for the sellers who participate in paid programs that pull them deeper into Amazon's seller ecosystem. Amazon has built tremendous trust with consumers after 25 years of 'customer obsession,' and it depends on this reserve of trust in the midst of an explosion of review pollution on its platform.

Critiques of how exactly Amazon governs its reviews space and whether its rules are effective in reducing review pollution may be relevant for third-party sellers and concerned shoppers, but they don't address the bigger picture. It's only because Amazon is so dominant in ecommerce, akin to "essential infrastructure" (Khan, 2017, p. 803) at least in the US, that the ways it shapes and constrains consumer reviews become so high stakes, making or breaking some businesses, for example, or allowing significant numbers of faulty or dangerous products to circulate in the marketplace, despite seemingly rave reviews. The US Federal Trade Commission, whose purview includes truth-inadvertising, has made stern inquiries and even brought a case against a company selling on Amazon in relation to manipulated reviews and false claims for its products (Musil, 2019). The Commission also insists that compensated reviews always be disclosed. But on balance, in the US at least, governance is ceded to the platforms, with some movement in just the last few years from both the House Judiciary Committee and Trade Commission to investigate the major tech platforms for practices that are anti-competitive or hurt small businesses. On March 25th, 2021, the House Energy and Commerce Committee conducted a hearing with the CEOs of Facebook, Google, and Twitter on the topic of "Disinformation Nation: Social Media's Role in Promoting Extremism and Misinformation." Notably absent was Amazon, despite the fact that its reviews space, content platforms, and recommendation algorithms have been implicated in the distribution and amplification of disinformation (DiResta, 2019). While regulators are starting to take notice of the most spectacular and brazen abuses of tech platforms, the broader issues of the outsized power of information gatekeepers like Amazon, and the ways they police themselves and others in situations when they have conflicting business incentives, seem currently beyond their reach. Meanwhile, the everyday, routinized nature of disinformation like review pollution contributes to the steady erosion of social trust in information, institutions, and other people. The damage done to our information environment by something as seemingly trivial as manipulated product reviews points to the need for systemic responses to the oligopolistic, infrastructural, and self-serving nature of tech platforms.

While consumer reviews were at one time a key reason for the trust that people developed for Amazon's ecommerce site, those same review spaces now threaten that trust. The star ratings only serve as effective promotion when people think they have informational value. Trust is, itself, a valuable commodity, but it's also more than that. Trust is fundamental to the social contract, and to our ability to communicate with and coordinate with others. As consumers become used to the idea that they have to be everyday detectives, combing through 
reviews or using third-party browser extensions to estimate which reviews are genuine in order to make a simple online shopping decision, they become more firmly interpellated into an emerging common sense about the contemporary internet: that no one can be trusted, and everything found online is the result of a complex, neverending contest for reputational capital among competing interests and powerful organizations. It's a lesson about being small and powerless, even though it all began as an effort to make the consumer feel like their voice, and the voices of their fellow consumers, mattered.

\section{Acknowledgments}

I would like to thank Dr. Claire Wardle, who provided key support for fieldwork and encouragement for my broader research interest on Amazon. I would also like to thank the members of the Media Reading Group, organized by Dr. Joshua Braun, who helped keep me moving forward on this project during the challenges of 2020-2021.

\section{Conflict of Interests}

The author declares no conflict of interests.

\section{References}

Amazeen, M. A., \& Muddiman, A. R. (2018). Saving media or trading on trust? The effects of native advertising on audience perceptions of legacy and online news publishers. Digital Journalism, 6(2), 176-195.

Amazon. (2020a). Community guidelines. https://www. amazon.com/gp/help/customer/display.html/ref= hp_left_v4_sib?ie=UTF8\&nodeld=GLHXEX85 MENUE4XF

Amazon. (2020b). Customer reviews. https://www. amazon.com/gp/help/customer/display.html/ref= hp_left_v4_sib?ie=UTF8\&nodeld=G3UA5WC 5S5UUKB5G

Amazon. (2020c). How are product star ratings calculated? https://www.amazon.com/gp/help/ customer/display.html/ref=hp_left_v4_sib?ie= UTF8\&nodeld=GQUXAMY73JFRVJHE

Anderson, E. T., \& Simester, D. I. (2014). Reviews without a purchase: Low ratings, loyal customers, and deception. Journal of Marketing Research, 51(3), 249-269.

Andrejevic, M., Hearn, A., \& Kennedy, H. (2015). Cultural studies of data mining: Introduction. European Journal of Cultural Studies, 18(4/5), 379-394.

Bialik, C. (2009, January 23). Let's rate the ranking systems of film reviews. The Wall Street Journal. https:// www.wsj.com/articles/SB123265679206407369

Broida, R. (2019, March 4). How to spot fake Amazon reviews. CNet. https://www.cnet.com/how-to/spotfake-reviews-amazon-best-buy-walmart

Bruce, D. M. (2010). Baedeker: The perceived 'inventor' of the formal guidebook-A Bible for travellers in the 19th century. In R. W. Butler \& R. A. Russell (Eds.), Giants of tourism (pp. 93-110). CABI.

Bucher, T. (2017). The algorithmic imaginary: Exploring the ordinary affects of Facebook algorithms. Information, Communication \& Society, 20(1), 30-44.

Charman-Anderson, S. (2012, August 28). Fake reviews: Amazon's rotten core. Forbes. https://www.forbes. com/sites/suwcharmananderson/2012/08/28/fakereviews-amazons-rotten-core/?sh=351af8797428

CPC Strategy. (2018). The 2018 Amazon shopper behavior study. http://learn.cpcstrategy.com/rs/ 006-GWW-889/images/2018-Amazon-ShopperBehavior-Study.pdf

Cronin, A. M. (2016). Reputational capital in 'the PR University': Public relations and market rationalities. Journal of Cultural Economy, 9(4), 396-409.

David, S., \& Pinch, T. (2006). Six degrees of reputation: The use and abuse of online review and recommendation systems. First Monday, 11(3). https://doi.org/ 10.5210/fm.v11i3.1315

Dawson, C. (2020, December 16). Amazon review the review feature to go. Tamebay. https://tamebay. com/2020/12/amazon-review-the-review-commentfeature-to-go.html

Dean, J. (2005). Communicative capitalism: Circulation and the foreclosure of politics. Cultural Politics, 1(1), 51-74.

Del Ray, J. (2020, February 14). Amazon can't end fake reviews, but its new system might drown them out. Vox: Recode. https://www.vox.com/recode/2020/2/ 14/21121209/amazon-fake-reviews-one-tap-starratings-seller-feedback

DiNucci, D. (1999). Fragmented future. Print, 53(4), 32.

DiResta, R. (2019, March 5). How Amazon's algorithms curated a dystopian bookstore. Wired. https:// www.wired.com/story/amazon-and-the-spread-ofhealth-misinformation

DiResta, R. (2018). Computational propaganda: If you make it trend, you make it true. The Yale Review, 106(4), 12-29.

Dod, R. (n.d.). Inside Amazon's A9 algorithm: What you need to know to rank products. Visiture. https:// www.visiture.com/blog/inside-amazons-a9algorithm-what-you-need-to-know-to-rank-products

Dwoskin, E., \& Timberg, C. (2018, April 23). How merchants use Facebook to flood Amazon with fake reviews. The Washington Post. https://www. washingtonpost.com/business/economy/howmerchants-secretly-use-facebook-to-flood-amazonwith-fake-reviews/2018/04/23/5dad1e30-439211e8-8569-26fda6b404c7_story.html

Dzieza, J. (2018, December 19). Dirty dealing in the \$175 billion Amazon marketplace. The Verge. https://www.theverge.com/2018/12/19/18140799/ amazon-marketplace-scams-seller-court-appealreinstatement

eMarketer Editors. (2020, February 28). Target cracks top 10 US ecommerce ranking. eMarketer. https:// 
www.emarketer.com/content/target-cracks-top-10us-ecommerce-ranking

Esposito, E., \& Stark, D. (2019). What's observed in a rating? Rankings as orientation in the face of uncertainty. Theory, Culture \& Society, 36(4), 3-26.

Feedvisor. (n.d.). How does Amazon's A9 search engine work? https://feedvisor.com/university/a9-searchengine

Goldhaber, M. H. (1997). The attention economy and the net. First Monday, 2(4/7). https://firstmonday.org/ article/view/519/440

Graham, T., \& Henman, P. (2019). Affording choice: How website designs create and constrain 'choice.' Information, Communication \& Society, 22(13), 2007-2023.

Greene, J. (2015, November 1). Amazon product reviews become haven for causes, conspiracies, rage. The Seattle Times. https://www.seattletimes.com/ business/amazon/amazon-reviews-hijacked-bycauses-conspiracies-rage

Hagemeier, H. (2012, June 20). Fake reviews abound online. The Bulletin. https://www.bendbulletin.com/ business/fake-reviews-abound-online/article 757e275a-0900-5bbd-8d0c-7862fea222a5.html

Harp, S. (2002). The Michelin Red Guides: Social differentiation in early twentieth century French tourism. In R. Koshar (Ed.), Histories of leisure (pp. 191-214). Berg Publishers.

He, S., Hollenbeck, B., \& Proserpio, D. (2020). The market for fake reviews. http://dx.doi.org/10.2139/ssrn. 3664992

Hearn, A. (2010). Structuring feeling: Web 2.0, online ranking and rating, and the digital 'reputation' economy. Ephemera: Theory and Politics in Organization, 10(3/4), 421-438.

Katz, G. (2010, April 23). Author says he wrote vicious reviews, not his wife. The Hartford Courant. https:// www.courant.com/sdut-author-says-he-wrotevicious-reviews-not-his-wife-2010apr23-story.html

Keane, J. (2018, March 22). Post-truth politics and why the antidote isn't simply 'fact-checking' and truth. The Conversation. https://theconversation.com/ post-truth-politics-and-why-the-antidote-isntsimply-fact-checking-and-truth-87364

Kelley, A. J. (2017, June 2). Amazon's early reviewer program: What you need to know. Viral Launch. https:// blog.viral-launch.com/news-updates/amazonnews-updates/amazon-early-reviewer-program

Kennedy, H., \& Hill, R. L. (2018). The feeling of numbers: Emotions in everyday engagements with data and their visualization. Sociology, 52(4), 830-848.

Khan, L. (2017). Amazon's antitrust paradox. The Yale Review, 126, 710-805.

Kozinets, R. V., Gershoff, A. D., \& White, T. B. (2020). Introduction to special issue-Trust in doubt: Consuming in a post-truth world. Journal of the Association for Consumer Research, 5(2), 130-136.

Kuehn, K. M. (2017). Brand local: Consumer evaluations as commodity activism on Yelp.com. Journal of Consumer Culture, 17(2), 205-224.

Luca, M. (2011). Reviews, reputation, and revenue: The case of Yelp.com (Working Paper No. 12-016). Harvard Business School. https://www.hbs.edu/faculty/ Publication\%20Files/12-016_a7e4a5a2-03f9-490db093-8f951238dba2.pdf

Marcus, J. (2004). Amazonia. The New Press.

Marth. (2016, April). Is Amazon watering down the product review system? [Discussion post]. Amazon Services Seller Forums. https://sellercentral.amazon. com/forums/t/is-amazon-watering-down-theproduct-review-system/173509

Masters, K. (2021, March 22). A short history of Amazon's product review system, and where we are today. Forbes. https://www.forbes.com/sites/kirimasters/ 2021/03/22/a-short-history-of-amazons-productreview-ecosystem/?sh=6b1faf7d2b86

Matsakis, L. (2019, May 25). What do Amazon's star ratings really mean? Wired. https://www.wired.com/ story/amazon-stars-ratings-calculated

McGinn, B., \& Segal, P. (2019). The Amazon roadmap: How innovative brands are reinventing the path to market. Authority Publishing.

Mendoza, J. (2015, October 19). Amazon sues 1,000 fake reviewers. Can online retailers restore consumer trust? The Christian Science Monitor. https://www. csmonitor.com/Business/2015/1019/Amazon-sues1-000-fake-reviewers.-Can-online-retailers-restorecustomer-trust

Mooney, P. (2011, December 18). Klipsch 5.1 Home Theater System sale released on Amazon. Business Examiner.

Musil, S. (2019, February 26). FTC settles its first case over fake paid reviews on Amazon. CNet. https:// www.cnet.com/news/ftc-settles-its-first-case-overfake-paid-reviews-on-amazon

Nguyen, N. (2018a, May 7). Inside Amazon's fake review economy. Buzzfeed News. https://www. buzzfeednews.com/article/nicolenguyen/amazonfake-review-problem\#.yudMX6AwL

Nguyen, N. (2018b, May 29). Here's another kind of review fraud happening on Amazon. Buzzfeed News. https://www.buzzfeednews.com/article/ nicolenguyen/amazon-review-reuse-fraud

Nguyen, N. (2019a, October 14). Amazon sellers are using Facebook chatbots to cheat their way to good reviews. Buzzfeed News. https://www. buzzfeednews.com/article/nicolenguyen/amazonsellers-facebook-chatbots-fake-reviews

Nguyen, N. (2019b, November 20). Her Amazon purchases are real: The reviews are fake. Buzzfeed News. https://www.buzzfeednews.com/article/ nicolenguyen/her-amazon-purchases-are-real-thereviews-are-fake

Noonan, T. (2016, April 28). How ReviewMeta works [Video]. ReviewMeta: How It Works. https:// reviewmeta.com/blog/how-it-works 
Novak, A. (2021). The new review economy: Third-party review sites, reputation, and neo-liberal public relations in the digital age. Routledge.

O'Reilly, T. (2005, September 30). What is Web 2.0? O'Reilly. https://www.oreilly.com/pub/a/web2/ archive/what-is-web-20.html

Oxford Languages. (2016). Word of the year 2016. https://languages.oup.com

Report: Fake online reviews soar in pandemic. (2020, November 14). The Bismarck Tribune.

Reusable kids' icePack from Xino Sports receives accolates from Amazon shoppers. (2020, November 13). PR Newswire. https://www.prnewswire.com/ news-releases/reusable-kids-ice-pack-from-xinosports-receives-accolades-from-amazon-shoppers301172621.html

Rubin, B. F. (2015, June 19). Amazon looks to improve customer-reviews system with machine learning. CNet. https://www.cnet.com/news/amazonupdates-customer-reviews-with-new-machinelearning-platform

Scott, A. (2020, January 24). Amazon restricts reviews of "American Dirt" [Radio broadcast]. Marketplace. https://www.marketplace.org/2020/01/24/ amazon-restricts-reviews-of-american-dirt

Shepard, W. (2017, February 14). How Amazon's wooing of Chinese sellers is killing small American businesses. Forbes. https://www.forbes.com/sites/wadeshepard/ 2017/02/14/how-amazons-wooing-of-chinesesellers-is-hurting-american-innovation/?sh= 1911 bffa1df2

Srnicek, N. (2017). Platform capitalism. Polity Press.
Suddath, C. (2005, October 25). Lit crit for dummies*. Nashville Scene. https://www.nashvillescene.com/ news/lit-crit-for-dummies/article_a175bd37-1d8952cb-aa91-0b374ba0e3cd.html

Terranova, T. (2000). Free labor: Producing culture for the digital economy. Social Text, 18(2), 33-58.

The Better Business Bureau. (2017, October 27). BBB says fake online reviews undermine consumer confidence. The Hutchinson News. https://www. hutchnews.com/article/20171026/news/171029065

Tsukayama, H. (2013, May 22). How much power does a Yelp review have? The Washington Post. https://www.washingtonpost.com/business/ technology/how-much-power-does-a-yelp-reviewhave/2013/05/22/6b8f961c-c210-11e2-8c3bOb5e9247e8ca_story.html

Turner, E., \& Rainie, L. (2020, March 5). Most Americans rely on their own research to make big decisions, and that often means online searches. Pew Research Center. https://www.pewresearch.org/fact-tank/ 2020/03/05/most-americans-rely-on-their-ownresearch-to-make-big-decisions-and-that-oftenmeans-online-searches

Wells, J. R., Weinstock, B., Danskin, G., \& Ellsworth, G. (2019). Amazon.com, 2019. Harvard Business Review. Article 9-716-402.

$\mathrm{Xu}, \mathrm{Y}$. (2021). Two studies on individuals' perception on online disinformation [Dissertation, The Hong Kong Polytechnic University]. The Hong Kong Polytechnic University. https://theses.lib.polyu.edu.hk/ handle/200/10992

\section{About the Author}

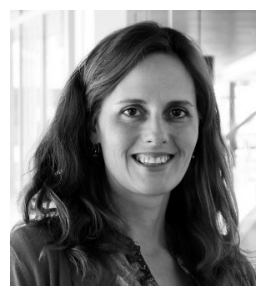

Emily West is Associate Professor in the Department of Communication at the University of Massachusetts Amherst, and the Author of Buy Now: How Amazon Branded Convenience and Normalized Monopoly (MIT Press, 2022). She is Co-Editor of The Routledge Companion to Advertising and Promotional Culture, and her articles about media and culture appear in journals such as Surveillance \& Society, International Journal of Communication, Popular Communication, and Feminist Media Studies. 